\title{
Etnomatemática e Educação Infantil: O que Tem no Universo?
}

\section{Ethnomathematics and Early Childhood Education: What's Out There in the Universe?}

\author{
iD Sabrina Monteiro ${ }^{1}$ \\ Deda Maria Giongo ${ }^{1}$ \\ iD Jacqueline Silva da Silva ${ }^{1}$ \\ 'Universidade do Vale do Taquari (Univates), Lajeado, RS, Brasil. \\ Autora correspondente: smonteiro@universo.univates.br
}

Resumo: Este artigo apresenta-se como parte de uma pesquisa de Mestrado que tem como objetivo analisar uma situação de aprendizagem efetivada com crianças de quatro e cinco anos de uma escola de Educação Infantil, do interior do estado do Rio Grande do Sul, Brasil. A situação foi adaptada de uma proposta de Longhini, O Universo representado em uma caixa, considerada uma introdução para o Ensino de Astronomia. Com aproximações etnográficas, a pesquisa teve uma abordagem qualitativa. Os dados coletados foram apreciados através da Análise Textual Discursiva e indicaram que, por meio das reflexões entre os achados, comparações estabelecidas entre as crianças entre suas construções mostram que elas possuem diversas ideias iniciais sobre o universo, porém diferentes. astronomia.

Palavras-chave: Etnomatemática; Educação infantil; Sistema solar; Ensino da

Abstract: The present study is part of a Master's degree research that aims at analyzing the effects of learning among children aged four and five years in a School of Early Childhood Education in the countryside of Rio Grande do Sul, Brazil. The situation was adapted from a proposal by Longhini, The universe represented in a box, which is considered as an introduction to the Teaching of Astronomy. By means of ethnographic approximations, the research followed a qualitative approach. The collected data were subjected to Discursive Textual Analysis. The resulting information has indicated that through the reflections on the findings, comparisons established between the children and their constructions, children have a range of initial ideas about the universe, but they think differently from one another. teaching.

Keywords: Ethnomathematics; Early childhood education; Solar system; Astronomy 


\section{Introdução}

O propósito desta escrita é analisar como a Etnomatemática contribui para os processos de ensino na Educação Infantil em uma escola localizada no Município de Lajeado, Rio Grande do Sul (RS). Dessa forma, o presente estudo resulta de uma situação de aprendizagem adaptada de Longhini (2009).

Cabe destacar que, inicialmente, a pesquisadora se dirigiu à escola para observar as crianças e descobrir uma temática emergente do cotidiano delas, seja nas brincadeiras, nas conversas paralelas e até nas horas de parque, o que totalizou uma estada, de mais ou menos, sessenta horas. Com isso, constatou-se que fortemente emergiam considerações referentes ao Sistema Solar e ao Céu, inclusive nomes de planetas e quem habitava no firmamento.

Partindo da temática já estabelecida, com o intento de aprimorar as situações de aprendizagem pensadas em um primeiro momento, buscaram-se, no Portal da Capes, trabalhos que aproximassem a Etnomatemática da Educação Infantil. Apenas dois estudos foram apontados, ambos do Mestrado de Ciências Exatas da Universidade do Vale do Taquari (Univates): Rodrigues (2010) e Souza (2015). Cabe informar que a dissertação de Cimadon (2018), que também abrange a temática, foi defendida recentemente, não constando, ainda, do Portal.

Dessa forma, este artigo assume um caráter reflexivo, uma vez que se propõe a analisar a situação de aprendizagem $O$ universo representado em uma caixa. Inicialmente, realizam-se as considerações iniciais, contextualizando o ambiente no qual a situação foi desenvolvida. Após são descritos os materiais e métodos utilizados, seguidos de uma reflexão sobre a aplicação da situação proposta e análise dos dados coletados. Ao final, dissertam-se algumas considerações relevantes à pesquisa.

\section{Materiais e Métodos}

Este estudo tem uma abordagem qualitativa, partindo da premissa de que a situação de aprendizagem proposta é definida pela produção de dados, de modo descritivo, cabendo, dessa forma, ao pesquisador o papel de principal produtor do corpus. À vista disso, esta pesquisa assume uma abordagem qualitativa, alicerçada no referencial teórico de Bogdan e Biklen (1994).

Pelo fato de se tratar de um estudo da Etnomatemática na Educação Infantil, com crianças de quatro e cinco anos, estudantes de um Escola Municipal de Educação Infantil Lajeado, estado do Rio Grande do Sul (RS), pode-se afirmar que existem aproximações com uma pesquisa de abordagem etnográfica, uma vez que o estudo buscou compreender a cultura, crenças e valores que os alunos já possuíam. Assim sendo, André (1998, p. 19) descreve esse tipo de pesquisa como "[...] uma tentativa de descrever uma cultura".

A atividade aqui descrita é uma adaptação de Longhini (2009), a qual possibilitou a construção de um Sistema Solar de forma tridimensional, em forma de caixa, em um suporte com canos de PVC de, aproximadamente, $1 \mathrm{~m}^{3}$. As crianças tiveram à sua disposição diversos materiais, como folhas, bolas de isopor, massa de modelar, tinta, canetinhas, lápis para criarem o que imaginavam existir no céu. À medida que as concluíam, suas produções eram penduradas com fios de nylon na caixa. Acredita-se que a situação contemplou as ideias propostas por Smole (2000, p. 108) quando sustenta que “[...] faz-se necessário que sejam 
propiciadas condições para que os alunos comecem a desenvolver, talvez em um certo sentido ampliar, uma 'linguagem de espaço'".

Durante as construções, a pesquisadora circulava entre os alunos para verificar suas ações e anotá-las em seu diário de itinerância (BARBIER, 2004). Além disso, contava com dois gravadores e duas filmadoras dispostas em lugares aleatórios na sala com a finalidade de capturar o maior número de dados possíveis para posterior análise. Cabe destacar que, mediante a autorização dos pais, que assinaram o Termo de Consentimento Livre e Esclarecido, neste estudo, foi utilizado o nome das crianças. Quanto à análise de dados coletados, inicialmente, levou-se em consideração as pressuposições de Bogdan e Biklen (1994, p. 205), reiterando que é o

[...] processo de busca e de organização sistemático de transcrições de entrevistas, de notas de campo e de outros materiais que foram sendo acumulados, com o objetivo de aumentar a sua própria compreensão desses mesmos materiais e de lhe permitir apresentar aos outros aquilo que encontrou. A análise envolve o trabalho com os dados, a sua organização, divisão em unidades manipuláveis, síntese, procura de padrões, descoberta dos aspectos importantes e do que deve ser aprendido e a decisão sobre o que vai ser transmitido aos outros.

Dessa forma, optou-se, nesta pesquisa, pela utilização da Análise Textual Discursiva de Moraes e Galiazzi (2007, p. 112), que a descrevem como um "[...] processo de desconstrução seguido de reconstrução, de um conjunto de materiais linguísticos e discursivos, produzindose, a partir disso, novos entendimentos sobre os fenômenos e discursos investigados". Outro fator primordial para escolha deste tipo de análise infere um olhar mais extensivo proporcionado aos pesquisadores quando analisam os dados coletados.

Cumpre destacar que esse tipo de análise preconiza três fases distintas. A primeira é tida como a Unitarização, também nomeada por pesquisadores de momento do caos, que contém a coleta com todos os dados sem nenhuma separação. Na segunda, a Categorização, o pesquisador, de acordo com algumas categorias que emite ser importantes, categoriza seus dados coletados para que, na última fase, na Captura dos Emergentes, obtenham-se novas contribuições referentes à pesquisa em estudo. Destarte, Moraes (2003, p. 192), neste pressuposto, enfatiza que "[...] pode ser compreendida como um processo auto-organizado de construção de compreensão em que novos entendimentos emergem de uma sequência recursiva de três componentes".

\section{Resultados e Discussões}

Nesta seção descreve-se a situação de aprendizagem adaptada de Longhini (2009), considerada uma introdução para o ensino de Astronomia, com o intento de provocar as crianças sobre o que havia no céu. Por meio dela, o autor propõe uma reflexão mental sobre o universo representado em um modelo tridimensional.

Primeiramente, montou-se uma caixa de, aproximadamente, $1 \mathrm{~m}^{3}$, utilizando-se canos de PVC. Cumpre frisar que o objeto despertou imensa curiosidade nas crianças, que desejavam saber de que forma seria utilizado. Então, explicou-se que seria feita uma representação do Sistema Solar e que deveriam construir o que imaginavam que lá existisse. Para tanto, elas, de forma organizada, sentaram-se às mesinhas, sendo-Ihes disponibilizados diversos materiais: 
papel colorido, folha de desenho, massa de modelar, tinta, bolinhas de isopor de diferentes tamanhos, canetinhas, lápis de cor, giz de cera, papel crepom e EVA.

A ideia inicial era que as crianças recebessem as folhas e fizessem recortes para serem colocados no Planetário. Porém, rapidamente, elas mesmas escolheram uma e começaram a desenhar. Pondera-se, dessa forma, que o desenho é uma forma de pensar o ensino, oportunizando "[...] a cada indivíduo atingir seu potencial criativo", o que, de acordo com D’Ambrósio (2015, p. 31), é uma maneira de "facilitar a ação" e a interação comum. Por sua vez, Costi (2018) infere que ele é uma alternativa para tornar as aulas dinâmicas e mais interessantes.

Enquanto desenhavam, as crianças eram questionadas sobre o que estavam produzindo, sendo várias as respostas: pingos de chuva, unicórnios, nuvens, entre outras. Ao analisá-las, constatou-se que expressavam "[...] a imaginação, pois a criança observa a realidade e registra desta aquilo que Ihe é significativo, sendo os diversos recortes dessa realidade combinados imaginativamente e objetivados por meio do desenho" (NATIVIDADE; COUTINHO; ZANELLA, 2008, p. 12). Assim, foi possível observar os elementos de sua compreensão sobre o meio no qual estavam inseridas.

Nessa mesma perspectiva, ao se examinarem os desenhos, buscou-se saber o que as crianças comentavam a respeito de suas produções, pois, "[...] para compreender o desenho infantil e aquilo que seu autor diz por meio de traços e cores lançados em uma folha de papel, necessário se faz escutar o que o próprio autor fala sobre sua produção" (NATIVIDADE; COUTINHO; ZANELLA, 2008, p. 12). No mesmo sentido, Wortmann (2002, p. 81) destaca que "[...] as linguagens são centrais para o significado e para a cultura, por serem os repertórios chaves de valores e de códigos que dão sustentação aos diálogos", entrelaçandoos diretamente com a Etnomatemática.

Assim, utilizando dois gravadores e duas câmeras espalhadas pela sala, a pesquisadora se aproximou das duplas e Ihes perguntou o que estavam desenhando. As componentes da primeira desenharam o Sol representado pela cor azul, justificando que: "Nós fizemos o Sol azul, porque o Sol fica no céu, e o céu é azul da cor do Grêmio". Tal comparação permitiu afirmar que as relações emergentes da prática viabilizaram a construção de conhecimentos, oportunizando "[...] aos sujeitos interpretarem o mundo de maneira mais ou menos parecida e a se tornarem membros de uma cultura" (WORTMANN, 2002, p. 81), evidenciando o time de futebol.

Quanto ao exposto, Minsky (1986) afirma que, talvez, os desenhos infantis não satisfaçam as expectativas dos adultos, mas, quase sempre, solucionam e mostram as versões próprias das crianças para os problemas a elas propostos. Acredita-se também que destacar o azul do Grêmio contribuiu para "[...] compartilhar conhecimento e compatibilizar comportamento estão sintetizadas as características de uma cultura" (D'AMBRÓSIO, 2015, p. 19).

Cimadon (2018), em sua pesquisa/intervenção, teve por objetivo investigar os saberes que emergiram das crianças de cinco e seis anos de idade, propondo-lhes situações de aprendizagem vinculadas às Noções Geométricas Espaciais. A pesquisadora enfatizou, ao longo das reflexões, nos dados empíricos, que o interessante e gratificante de interagir com crianças é o fato de elas serem espontâneas e criativas. Cimadon (2018) também fez uso, em suas análises, das representações feitas pelas crianças por meio de desenhos sobre o bairro da escola destacando o relevo e as moradias. Ato contínuo, utilizou a própria estrutura escolar para a problematização de aspectos atinentes à Geometria Espacial. A autora percebeu 
[...] a riqueza de detalhes e como a discussão e as observações realizadas durante o passeio aparecem no registro" (CIMADON, 2018, p. 90). Ademais, ressaltou que "[...] as representações que aparecem [...] expressam saberes oriundos de abordagens culturais, uma vez que no momento da rodinha essa mesma criança (A3) apontou que o bairro tem curvas e que havia aprendido sobre elas com seu pai".

Ao levar em consideração a importância na Educação Infantil, "[...] o desenho expressa não apenas fantasia, mas também aquilo que a criança se apropria e o que ela significa da realidade [...]" (FERREIRA, 2008). Dessa forma, ao desenhar, ela propõe uma interação com o meio e manifesta a sua compreensão de mundo. Nesse sentido, Costi $(2018$, p. 40) enfatiza que, "[...] ao propor atividades de desenho, inseridas na prática pedagógica, foi possível observar a expressão da criatividade e a manifestação de alguns traços que trazem de seu meio cultura". Ao contemplar essa proposição, destaca-se que Estevão, desde o início, afirmou que, no céu, existiam flores e grama.

Nesse mesmo viés, Micael, que formava a dupla com Estevão, afirmou que, "[...] no céu, tem muitas coisas coloridas, que podem ser animais ou flores." Acredita-se ser importante comentar que, por meio das manifestações de cores, a criança demonstrou o entendimento que possuía, expressando seus sentimentos e desejos daquele momento, fato que remete à pesquisa de Ferreira (2008).

Ao partir do pressuposto de que Micael fez muitos rabiscos, Smole (2000, p. 104) ressalta que, "[...] quando a criança rabisca, ela não está concebendo o objeto e o espaço, pois nem o objeto nem o espaço estão, num primeiro momento, sendo percebidos na sua totalidade". Aqui é possível verificar semelhanças com o pensamento de D'Ambrósio (2015, p. 18):

Todo indivíduo vivo desenvolve conhecimento e tem um comportamento que reflete esse conhecimento, que por sua vez vai modificando em função dos resultados do comportamento. Para que cada indivíduo, seu comportamento e seu conhecimento estão em permanente transformação, e se relacionam numa relação que poderíamos dizer de verdadeira simbiose em total interdependência.

Ainda no que se refere aos rabiscos desenhados por Micael, cumpre informar que Lucas seguiu a mesma linha no que tangencia a ideia de céu e de universo. Sobre isso, ele esclareceu que: "Eu fizo céu azul e vermelho, azul do Grêmio e vermelho do Inter". Acredita-se que o menino expressou desejos e sensações representados em formas de rabiscos e garatujas, o que direciona aos apontamentos de Smole (2000) quando explana o desenho como forma de expressão de pensamento. Em relação ao campo da Etnomatemática, fica explícito que a cultura não é algo pronto, mas está "[...] constantemente reatualizando-se e adquirindo novos significados, ou seja, produto e produtores de cultura". (KNIJNIK; WANDERER, 2012, p. 26).

É produtiva, portanto, a troca de conhecimentos advinda das interações e comparações das situações do dia a dia. Comumente a isso, Cimadon (2018) enfatiza que a criança é um sujeito imerso de informações, conhecimentos culturais adquiridos em suas vivências e, ao frequentar a pré-escola, expõe aos demais o que sabe, viu e experimentou, de forma a expressar situações inerentes ao seu cotidiano, perfazendo a Geometria Espacial. Para ela, 
Já no primeiro encontro, percebi que os saberes matemáticos iriam surgir de forma espontânea. Durante o passeio pelo bairro, observando a vizinhança e considerando as imensas 'subidas' e 'descidas' - assim nomeadas pelas crianças as declividades existentes - ao serem questionadas sobre o esforço físico que estavam exercendo para conseguirem subir e sobre a localização da escola [...] (CIMADON, 2018, p. 96).

Nesse dia, João esteve sozinho em sua classe, pois a colega com quem faria a dupla não compareceu. Ao observá-lo constatou-se que construía figuras que se assemelhavam a círculos, explicando que estava representando muitos planetas coloridos. Esse aspecto lembram Natividade, Coutinho e Zanella (2008, p. 11) quando afirmam que "[...] o desenho é uma forma de linguagem" e, como tal, "[...] tem papel importante tanto no desenvolvimento da capacidade cognitiva quanto na expressão da criatividade".

Keila, em suas representações, expressou: "Eu fiz a profe Sabrina princesa no seu castelo amarelo, no planeta dos unicórnios e lá tem um arco-íris bem colorido. Por isso, ela está sorrindo, eu também queria estar morando lá junto com a profe princesa Sabrina." Embora representasse o arco-íris, as nuvens e o Sol, Keila ainda imaginava um planeta de unicórnios. Para Smole (2000), a criança encontra no desenho um recurso importante para a comunicação e a expressão de sentimentos, vontades e ideias, o que ficou fortemente destacado na enunciação da menina.

Ao ser questionada sobre o seu desenho, Keila iniciou sua explicação se referindo ao Planeta dos unicórnios: "[...] ele existe de verdade, pois eu vi no desenho da Sofia". Dessa forma, ela descreveu, com detalhes, que, no Planeta, predominavam as cores azul, amarelo, rosa e laranja, exatamente as que ela havia utilizado. Quanto a isso, Costi (2018, p. 40) afirma que "[...] a forma como as crianças se expressam por meio do desenho tem relação com questões culturais". Assim, entende-se que as crianças simbolizavam algo que fazia parte das suas ideias iniciais sobre o Céu, configurando, de fato, a sua realidade.

Na mesma proposta, Joana fez um desenho diferenciado dos seus colegas:

Eu fiz o céu, no meu céu, tem um monte de estrelas, só que tem uma estrela que é diferente, ela é vermelha, essa estrela é o planeta Marte. Minha mãe já me explicou isso, e as outras quase cinquenta estrelas que eu desenhei podem ser outras estrelas ou somente planetas, como Marte e aquele dos anéis.

Por meio da análise do desenho e o entrecruzamento com a Etnomatemática, as questões culturais existentes no desenho de Joana configuram que

[...] o modo como estes processos se desenvolvem e se objetivam variam em razão das condições sociais e culturais, historicamente produzidas e particularmente apropriadas em razão dos lugares sociais que cada pessoa ocupa na trama das relações cotidianas. (NATIVIDADE; COUTINHO; ZANELLA, 2008, p. 11).

Segundo Moreira (2011), a criança desenha para expressar algo e falar de si mesma. Nesse sentido, acredita-se que Joana externou esses sentimentos ao salientar que a mãe lhe explicara sobre a "estrela vermelha ser Marte". Ao ponderar sobre os conhecimentos da menina quando ela justifica seu desenho e examinar as diferenças culturais com aproximações etnomatemáticas, pressupõe-se que os saberes trazidos de casa e mais as interações com os colegas fizeram com que as crianças atribuíssem novas ideias sobre o universo, reiterando a atualização dos conhecimentos. 
Portanto, acredita-se que, por meio do desenho, é possível externar as representações reais, visíveis no dia a dia, bem como as imaginárias, o que ficou evidenciado quando Keila se referiu ao "planeta dos unicórnios". Nessa perspectiva, Larios de Rodríguez e Caballero Sahelices (2005) apontam que, nem sempre, as pessoas têm consciência de suas ideias de universo, o que faz com que muitas delas se sintam perplexas e com dificuldades perante o fato de ter que representá-lo e, talvez, pela primeira vez, serem impelidas a pensar sobre isso.

Essa perspectiva se aproxima dos estudos de Malaguzzi (1999) para enfatizar que as crianças foram capazes de construir mapas para a sua aprendizagem. Pensa-se que, ao organizar a distribuição das estrelas e expressar seu pensamento, Joana demonstrou seus conhecimentos e também levou em consideração o que aprendera com sua mãe. Nesse sentido, reporta-se às considerações de Giongo (2004, p. 204) quando ela atenta "[...] em identificar práticas daquele mundo fabril". Por sua vez, a pesquisadora se propôs a analisar os "saberes cotidianos" que faziam parte da cultura das crianças.

Para representarem, por meio de desenhos, o que imaginavam existir no céu, as crianças exploraram os diversos tipos de materiais, tendo como foco a situação de aprendizagem $O$ universo em uma caixa de Longhini (2009). Uma das ferramentas foi a massinha de modelar, disposta em diferentes cores, com o intuito de levá-las a criar o que achavam pertinente. Elas podiam escolher quantas fossem necessárias e utilizá-las em sua construção.

Muitas crianças iniciaram desenhando o Sol. O de Keila é cor-de-rosa, pois, segundo ela, "[...] no planeta dos unicórnios, eu imagino que o Sol seja rosa, e você acredita que rosa é a minha cor preferida?" Joana, insatisfeita com o que sua colega expressara, retrucou: "Keila, você sabe que não existe planeta dos unicórnios, e que o Sol é sempre amarelo, como o meu, em qualquer planeta." As enunciações das duas meninas remeteram novamente às ideias de Cimadon (2018), que sustenta que as crianças, ao ingressarem na Educação Infantil, passam a interagir com diferentes culturas, como as dos adultos que estão à sua volta e dos seus colegas, que possuem histórias e tradições culturais. Dessa forma, elas se deparam com a existência de outras ideias, ou seja, diferentes das suas.

Joana desenhava seu Sol amarelo, fazendo uso da massinha de modelar. Nesse instante, questionou-se Keila sobre as colocações de Joana. Pensativa, expressou: "Jô, acho que é verdade, o Sol não é rosa, ele é amarelo, eu não lembro de olhar para o céu e enxergar Sol cor-de-rosa." Ao assumir as posições de Longhini (2009) fomentou-se a discussão entre os participantes de modo que diferentes ideias pudessem ser valorizadas e analisadas pelos pares.

Acredita-se que as considerações de Joana e Keila foram muito valiosas, pois explicitaram que "[...] a produção humana, não está, de uma vez por todas, fixa, determinada, fechada nos seus significados, não sendo entendida como algo consolidado, um produto acabado, homogêneo" (KNIJNIK; WANDERER, 2006, p. 5). Aqui, novamente, destaca-se a importância das interações na construção de saberes.

Ao trabalhar com as bolinhas de isopor, as crianças representaram diferentes tipos de planetas; entre eles, Terra, Marte e o dos Anéis. Marte sempre foi considerado o Planeta vermelho, ideia proferida por Sara enquanto desenhava: "Eu fiz Marte, é o planeta em que mora os marcianos, por isso é vermelho e eu já vi na televisão." Nesse sentido, Souza (2015, p. 86) assevera que "[...] o desenvolvimento de atividades que envolvem o conhecimento da criança e a sua realidade oportuniza a criança expressar-se de uma forma dinâmica e espontânea, empregando a linguagem simples do cotidiano". 
Partindo dessas acepções, Giongo e Knijnik (2009) inferem a necessidade de estabelecer ligações entre a Matemática Escolar e a não Escolar. Nesse sentido, a presença da Etnomatemática se faz necessária já na Educação Infantil, sendo uma forma de valorizar os conhecimentos prévios de cada criança, o que se buscou salientar nesta pesquisa. Com o auxílio de fio de nylon, colocaram-se as construções dos alunos que representavam o universo na referida caixa.

Finda a organização, dialogou-se sobre a caixa construída, momento em que percebeu-se que a reprodução do universo em um pequeno espaço gerou um sentimento de incompreensão em algumas crianças em função da faixa etária e das ideias iniciais de cada uma. Parte delas conseguiu analisar o Sistema Solar como uma forma de representação sem a preocupação com medidas e escalas. Outra, por sua vez, mesmo com a interação dos colegas, da professora titular e da pesquisadora, não abstraiu que se fez apenas uma encenação. Nesse sentido, Minsky (1986) afirma que a configuração do espaço só faz sentido quando se percebe a necessidade de estabelecer comparações. Portanto, inicialmente, não foi possível estabelecer, de forma ampla, as comparações idealizadas; entretanto, como já descrito, elas aconteceram em outro momento da pesquisa. Congruente a isso, Smole (2000) assegura que, para as crianças atingirem a compreensão espacial, é preciso dar-lhes oportunidade de explorar e comparar tamanhos, direção e posição no espaço.

Ademais, ao analisar atentamente as construções por meio da Etnomatemática e buscar um olhar especial sobre suas compreensões matemáticas, compreende-se que as crianças pertenciam a distintos meios culturais. A maneira de expressarem suas enunciações e construções, segundo Cimadon (2018), mostra que constroem conhecimentos em seus contextos familiares e, no ambiente escolar, a interação Ihes possibilita a reestruturação de conceitos. Nessa mesma perspectiva, Costi (2018) ressalta que, ao propor situações de desenho inseridas na prática pedagógica, é possível observar a expressão da criatividade e a manifestação de alguns traços que as crianças trazem de seu meio cultural.

Neste momento, cabe relembrar que Costi (2018) defendeu recentemente sua dissertação intitulada Processos produtivos, anos iniciais do ensino fundamental e ensino de matemática: um estudo etnomatemático. Seu objetivo foi investigar que potencialidades pedagógicas, para o ensino de Matemática, emergiriam de uma prática centrada nos processos produtivos de uma indústria frigorífica. Quanto aos resultados, a autora apresenta dois que merecem destaque: no primeiro, sublinha a importância da indústria frigorífica para a manutenção da escola na comunidade, uma vez que grande parte dos familiares da turma envolvida atuava na empresa mencionada. No segundo, aponta a necessidade de, nas práticas pedagógicas, os conteúdos de Matemática serem trabalhados já nos Anos Iniciais e versarem sobre o contexto das crianças.

Ademais, evidencia que os resultados mostram a potência dos referenciais teóricometodológicos para que se repensem os processos de ensino da Matemática, sobretudo nos Anos Iniciais do Ensino Fundamental. Cimadon (2018) e Costi (2018) fizeram, em suas pesquisas, também o uso do desenho, embasando suas percepções em Natividade, Coutinho e Zanella (2008) e, assim, observaram as manifestações culturais do seu meio, aspecto por elas destacado. 


\section{Considerações Finais}

Com o objetivo proposto neste estudo, analisar uma situação de aprendizagem decorrente de $O$ universo representado em uma caixa, com crianças de quatro e cinco anos da Educação Infantil, foi possível inferir diversas problematizações referentes ao Sistema Solar. Por meio de reflexões entre os achados, comparações estabelecidas entre as crianças e suas construções, estabelecidas como astros na construção do universo, identificou-se a diversidade de ideias iniciais que cada uma delas possuía sobre o assunto em questão.

Dessa forma, a interação e as discussões entre as crianças se fizeram fortemente presentes; enquanto algumas defendiam que o sol poderia ser cor-de-rosa, outras afirmavam ser amarelo. Em relação às duplas, ao mesmo tempo que um dos seus componentes queria desenhar um pingo de chuva, seu colega preferia fazer uma árvore, ideias com viés de divergência. Entretanto, trouxeram à tona os conhecimentos que elas haviam adquirido em casa, ou seja, ideias iniciais espaciais defendidas por Smolle (2000), o que vem totalmente ao encontro das concepções da Etnomatemática.

Quanto à Educação Infantil com aproximações da Etnomatemática, infere-se uma série de possibilidades a serem desenvolvidas. Acredita-se que, ao partir de temática emergente, a criança se considera pertencente àquela construção de significados obtidos não só por meio da situação de aprendizagem, mas por uma série de oportunidades que dela recorre, agregando, muitas vezes, conhecimentos aos que ela já possui; porém, de forma mais aprofundada.

Por fim, enfatiza-se a relevância da escuta sensível que transpassou toda pesquisa, preconizada por Barbier (2004). Assim, considera-se que, havendo a empatia e a sensibilidade de ouvir as crianças, é possível compreendê-las, uma vez que querem ser ouvidas. Elas trazem de casa uma série de saberes culturais, não só matemáticos, mas que envolvem as diferentes áreas; se forem ouvidas, também se sentirão pertencentes àquele espaço, comprometendose, assim, em agregar suas experiências. Essa postura foi adotada durante toda a pesquisa; por isso, os alunos participaram e se envolveram; consequentemente, os resultados obtidos foram satisfatórios desde o início.

\section{Referências}

ANDRÉ, M. E. D. A. Etnografia da prática escolar. 2. ed. São Paulo: Papirus, 1998.

BARBIER, R. A pesquisa-ação. Brasília: Liber Livro, 2004.

BOGDAN, R.; BIKLEN, S. A investigação qualitativa em educação. Porto: Porto Editora, 1994.

CIMADON, E. Geometria espacial e educação infantil: possibilidades para o ensino a partir de uma proposta etnomatemática. 2018. Dissertação (Mestrado em Ensino de Ciências Exatas) Universidade do Vale do Taquari, Lajeado, 2018.

COSTI, A. Processos produtivos, anos iniciais do ensino fundamental e ensino de matemática: um estudo etnomatemático. 2018. Dissertação (Mestrado em Ensino de Ciências Exatas) - Universidade do Vale do Taquari, Lajeado, 2018.

D'AMBROSIO, U. Etnomatemática: elo entre as tradições e a modernidade. 5. ed. Belo Horizonte: Autêntica, 2015. 
FERREIRA, N. S. C. Gestão democrática da educação: atuais tendências, novos desafios. 6. ed. São Paulo: Cortez, 2008.

GIONGO, I. M. Etnomatemática e educação no movimento sem terra. In: KNIJNIK, G.; WANDERER, F.; OLIVEIRA, C. J. (org.). Etnomatemática, currículo e formação de professores. Santa Cruz do Sul: EDUNISC, 2004. p. 203-218.

GIONGO, I. M.; KNIJNIK, G. Educação matemática e currículo escolar: um estudo das matemáticas da escola estadual de ensino técnico de Guaporé. Zetetiké, Campinas, v. 17, n. 32, p. 61-80, 2009.

KNIJNIK, G.; WANDERER, F. Currículo e formação de professores. Santa Cruz do Sul: EDUNISC, 2006.

KNIJNIK, G.; WANDERER, F.; GIONGO, I. M.; DUARTE, C. G. Etnomatemática em movimento. Belo Horizonte: Autêntica, 2012.

LARIOS DE RODRÍGUEZ, B.; CABALLERO SAHELICES, C. Representaciones mentales de profesores de ciencias sobre el universo y los elementos que incorporan en su estructura en general y los modelos cosmológicos que lo explican. In: ENCUENTRO IBEROAMERICANO SOBRE INVESTIGACIÓN BÁSICA EN EDUCACIÓN EN CIENCIAS, 2., 2004, Burgos. Actas [...]. Burgos: Universidad de Burgos, 2005. p. 654671.

LONGHINI, M. D. O universo representado em uma caixa: introdução ao estudo da astronomia na formação inicial de professores de física. Revista LatinoAmericana de Educação em Astronomia, São Carlos, n. 7, p. 31-42, 2009. DOI: https://doi.org/10.37156/RELEA/2009.07.031.

MALAGUZZI, L. História, ideias e filosofia básica. In: EDWARDS, C.; GANDINI, L.; FORMAN, G. As cem linguagens da criança: abordagem de Reggio Emilia na educação da primeira infância. Porto Alegre: Artmed, 1999. p. 57-98.

MINSKY, M. A sociedade da mente. Rio de Janeiro: Francisco Alves, 1986.

MOREIRA, M. A. Metodologias de pesquisa em ensino. São Paulo: Livraria da Física, 2011.

MORAES, R. Uma tempestade de luz: a compreensão possibilitada pela análise textual discursiva. Ciência \& Educação, Bauru, v. 9, n. 2, p. 191-211, 2003. DOI: http://doi.org/dv5vc4.

MORAES, R.; GALIAZZI, M. C. Análise textual discursiva. Ijuí: Ed. Unijuí, 2007.

NATIVIDADE, M. R.; COUTINHO, M. C.; ZANELLA, A. V. Desenho na pesquisa com crianças: análise na perspectiva histórico-cultural. Contextos Clínicos, São Leopoldo, v. 1, n. 1, p. 9-18, 2008.

RODRIGUES, N. I. Matemática, educação infantil e jogos e linguagem: um estudo etnomatemático. 2010. Dissertação (Mestrado em Ensino de Ciências Exatas) - Centro Universitário Univates, Lajeado, 2010.

SMOLE, K. C. S. A matemática na educação infantil: a teoria das inteligências múltiplas. Porto Alegre: Artmed, 2000.

SOUZA, A. S. Trabalhando com unidades de medidas e estimativas na educação infantil. 2015.

Dissertação (Mestrado em Ensino de Ciências Exatas) - Centro Universitário Univates, Lajeado, 2015.

WORTMANN, M. L. C. Análises culturais: um modo de lidar com histórias que interessam à educação. In: COSTA, M. V. et al. (org.). Caminhos investigativos Il: outros modos de pensar e fazer pesquisa em Educação. Rio de Janeiro: DP\&A, 2002. p. 73-92. 